\title{
Breast Cancer in Hong Kong, Southern China: The First Population-Based Analysis of Epidemiological Characteristics, Stage-Specific, Cancer-Specific, and Disease-Free Survival in Breast Cancer Patients: 1997-2001
}

\author{
Ava Kwong, BSc, MBBS, FRCS ${ }^{1,3}$, Oscar W. K. Mang, CStat, MSc ${ }^{2}$, Connie H. N. Wong, MSc ${ }^{1}$, W. W. Chau, MSc ${ }^{1}$, \\ The Hong Kong Breast Cancer Research Group ${ }^{3}$, and Stephen C. K. Law, FRCR ${ }^{2}$ \\ ${ }^{1}$ Division of Breast Surgery, Department of Surgery, Queen Mary and Tung Wah Hospital, The University of Hong Kong, \\ Hong Kong, China; ${ }^{2}$ The Hong Kong Cancer Registry, Hospital Authority, Hong Kong, China; ${ }^{3}$ Hospitals of the Hospital \\ Authority, Hong Kong, China
}

\begin{abstract}
Background. Cancer registries have been set up worldwide to provide information for cancer health planning. There are known variations in breast cancer incidence and mortality worldwide. However, breast cancer incidence, pathological characteristics, and survival data is still underreported in Asian countries. This is the first comprehensive population-based breast cancer study performed using population database of the Hong Kong Cancer Registry.

Methods. A retrospective review of medical records of 8,961 subjects who were diagnosed with breast cancer between January 1, 1997 to December 31, 2001 and followed up to December 31, 2007. Descriptive statistics were employed to analyze the epidemiological and clinical data. Estimates of overall, disease-free, and cancer-specific survival at 5 years were estimated by the Kaplan-Meier method and stage-specific relative survival rates were calculated.

Results. A total of 7,630 breast cancer patients' medical records and dataset were available during this period, and
\end{abstract}

Presented in part at The American Society of Breast Surgeons' Annual Meeting as a poster presentation, April 2011.

Names of contributors of the Hong Kong Breast Cancer Research Group are listed in the Acknowledgment.

(C) The Author(s) 2011. This article is published with open access at Springerlink.com

First Received: 18 April 2011;

Published Online: 17 August 2011

A. Kwong, BSc, MBBS, FRCS

e-mail: akwong@asiabreastregistry.com
7,449 subjects were eligible for the final analysis. Median follow-up was 84 months. A total of $47.4 \%$ were diagnosed with breast cancer at age 49 years and younger; $22.2 \%$, $46.9 \%, 10.8 \%$, and $4.1 \%$ presented at stages I, II, III, and IV, respectively. A total of $53.5 \%$ had ER-positive cancer, and $20.3 \%$ had HER2-positive cancers; $13.4 \%$ had triplenegative cancers. The relative, cancer-specific, and diseasefree survival rates at 5 years were $84 \%, 85.2 \%$, and $81.2 \%$, respectively.

Discussion. We performed the first comprehensive population-based breast cancer epidemiology study in Southern China using the Hong Kong Cancer Registry database. This provides a baseline study cohort for comparative studies with other Asian countries and Chinese who have migrated to the West.

Incidence rates of breast cancer have been increasing throughout the world. ${ }^{1}$ Breast cancer ranked the fifth, after lung, stomach, liver, and colon cancers, causing 460,000 deaths in 2008. ${ }^{2}$ Approximately 200,000 new cases are diagnosed with invasive breast cancer every year in the United States. ${ }^{3}$ Among women in the United States, breast cancer is the most common cancer and the second leading cause of cancer-related death in the United States. ${ }^{4}$ In Asia, the highest incidence $(53.7$ per 100,000) of breast cancers is in Manila, Philippines. ${ }^{5}$ An early study by Lin et al. investigated the epidemiology characteristics of breast cancer in a defined region of Northern Taiwan. ${ }^{6}$ The crude average annual incidence rate between 1964-1967 was 6.11 per 100,000 female population. ${ }^{6}$ Age-specific incidence rates showed a pattern similar in Japan and in the 
Chinese population of Singapore. The rates plateau in the middle-age and then declined in the older age groups. ${ }^{6}$ Mortality rates, however, consistently increased with age throughout the life span. ${ }^{6}$ A later study by Huang and colleagues demonstrated that the incidence of breast cancer ranked first in Taiwan, China, Singapore, Japan, and India in Asia. ${ }^{7}$ A study of 14,230 women age 25 years and older who died from breast cancer between 1995 and 2006 in Taiwan showed that the mortality rates increased dramatically with increasing age, and significant differences were observed for all age groups in the annual mortality rates from breast cancer. ${ }^{8}$ Shin et al. recently reported similar trends in breast cancer mortality in five Asian populations. ${ }^{9}$ Breast cancer mortality tended to decrease slightly in Hong Kong and Singapore after year 1990 except for women aged older than 70 years, in contrast to increased breast cancer death rates throughout the entire study period in Taiwan and Japan. ${ }^{9}$ Breast cancer death rates were almost the same in Taiwan and Japan before the 1990s, whereas it increased more steeply in Taiwan and then began rising more rapidly in Japan than in Taiwan after 1996. ${ }^{9,10}$ The most rapid increases in breast cancer mortality, and for all age groups, were in Korea. ${ }^{9}$ In Hong Kong, breast cancer overtook lung cancer to become the highest cancer incidence rate in women in $1994 .{ }^{11}$ A woman's risk of developing breast cancer before the age of 75 years is 1 per 21 and is increasing. ${ }^{12}$ The age-standardized incidence rates of breast cancer had been increasing from 32.5 per 100,000 in year 1983 to 35.0 per 100,000 in 2004 and further increased to 45.9 per 100,000 in $2008 .^{11,13,14}$

The difference in incidence rates and trends between Caucasians and Asian populations demonstrated great interest in further research in a still underexplored area in understanding the epidemiology of breast cancer in Asians. These ethnic differences are not only seen between Caucasians and Asians but also other ethnic groups. Hispanic women had a 1.5-fold increased risk of breast cancerrelated death, relative to non-Hispanic women (95\% confidence interval (CI), 1.2-1.8). ${ }^{15}$ Unlike the Caucasian population in the United States where the incidence rate of breast cancer peaked between age 45 and 55 years, the incidence rate for Hong Kong Chinese women peaked at age 40 years, i.e., earlier than that in the Caucasian population. ${ }^{16}$ Studies also demonstrated that the incidence rates of breast cancer in Caucasians continued to increase after the peak incidence age and reached menopause, whereas a plateau after the age of peak incidence was observed in Hong Kong females. ${ }^{17-19}$ Our previous study on breast cancer in Chinese female patients with operable breast cancer who received primary treatment found that the age distribution between Hong Kong Chinese and Chinese and Caucasian women residing in the United States were significantly different. ${ }^{20}$ Age-adjusted incidence found that a higher proportion of younger women presented with breast cancer compared with SEER data in the United States (12.1\% for the period of 2000-2004 in Hong Kong vs. 8\% in the United States). ${ }^{13,14,20,21}$ Incidence rates from 44 cancer registries in 15 countries in Asia published in "Cancer Incidence in Five Continents Volume IX" also showed great variations across Asia, with approximately threefold differences in both males and females. ${ }^{22}$ All of these findings showed great potentials of more in-depth investigations on the epidemiology of breast cancer in Southern Chinese.

To our knowledge, this is the first population-based study for female Chinese in Hong Kong, Southern China. The data would contribute much to understand the epidemiology of female breast cancer in Southern Chinese, and the results also could be compared with other populations in Asia and Western countries.

\section{METHODS}

This is a retrospective study based on the data collected through the Hong Kong Cancer Registry (HKCaR) with contribution from the prospectively collected database from the University of Hong Kong. HKCaR is a population-based registry established in 1963 which covers the entire Hong Kong population. ${ }^{12}$ The study has been approved by the institute review committee in Hong Kong. $\mathrm{HKCaR}$ also is a member of the International Association of Cancer Registries (IACR), providing international standard on data management and accuracy. HKCaR compiles reports on cancer statistics using demographic date, information on the anatomical site, and histopathology from different institutions in Hong Kong. HKCaR provides a framework for comparative geographical, epidemiological, and clinical research. Apart from patient demographic characteristics, such as age at diagnosis, the following data were collected or verified: date of diagnosis (accurate to the month), tumor side (left or right), last date seen, and status of disease when last seen; if death, the cause of death; if relapse, date of relapse, clinical management, such as mode of presentation, diagnosis, surgical treatment, and adjuvant therapy given; prognostic markers, such as tumor size, tumor type, tumor grade, lymph node status, stage at diagnosis, estrogen (ER), and progesterone receptors (PR) status, and HER2 status. Histological tumor grading was performed using the Bloom and Richardson classification system. ${ }^{23}$ Tumor staging was performed according to the American Joint Committee on Cancer criteria 6th edition (AJCC). ${ }^{24,25}$

Our database covered all 8,961 women who were diagnosed with breast cancer between January 1, 1997 and December 31,2001 . A total of $7,630(85.1 \%)$ medical 
records of women who were diagnosed with breast cancer for the period were successfully retrieved and reviewed both from the existing database of the University of Hong Kong and HKCaR. These records were matched with the HKCaR, Hong Kong Death Register, and databases from Hong Kong Hospital Authority's data warehouse. A total of 181 cases were excluded from the survival analysis for the following reasons: diagnosis based on death certificate only; unknown age at diagnosis; aged $\geq 100$ years; and completely lost to follow-up. The final analysis was based on the cohort of the remaining 7,449 patients followed up until December 31, 2007.

\section{Statistical Analysis}

Descriptive statistics were employed to describe the epidemiological, clinical, and diagnostic data. Mean and standard deviation (SD), and median if suitable, were used to express the numeric data. Overall survival (OS), cancerspecific survival (CSS), and disease-free survival (DFS) were calculated by using the life-table method. OS was defined as the time from diagnosis to death from any cause. CSS was defined as the time from diagnosis to death due to breast cancer. DFS among patients with stage I to III disease was defined as the time from diagnosis to the first event of recurrent disease or breast cancer death. These calculations were performed with the Statistical Package for the Social Sciences (SPSS) version 16.0 (IBM Corp, Somers, NY). Relative survival (RS) was computed by the ratio of the observed survival in the study population to the expected survival in the general population of the same age and sex. Expected survival rates were derived from life tables of the general Hong Kong population using the Hakulinen method. ${ }^{26,27}$ RS is a useful alternative measure that assesses the proportion of excess deaths that occur compared with the general population. All RS ratios were estimated using the SURV3 software. $^{28}$

\section{RESULTS}

A total of 7,449 invasive breast cancer patients between 1997 and 2001 were eligible for this study. Patient characteristics were tabulated in Table 1 . The mean and median of ages at diagnosis were 54 and 50 years, respectively. The incidence of breast cancer peaked at age 45 years, plateaued after age 55 years, and increased after age 70 years (Fig. 1). There is a slightly higher chance for the patients to have breast cancer in the left breast than right $(50.4 \%$ vs. $47.2 \%)$.

Of those with invasive cancers, $47.4 \%$ of our cohort was diagnosed with breast cancer at age 49 years or younger; $81.8 \%$ had invasive ductal carcinomas and $3.5 \%$ had
TABLE 1 Baseline characteristics of 7,449 patients with invasive breast cancer

\begin{tabular}{|c|c|c|}
\hline Characteristics & $N$ & $\%$ \\
\hline \multicolumn{3}{|l|}{ Age (years) } \\
\hline$<50$ & 3530 & 47.4 \\
\hline$>50$ & 3919 & 52.6 \\
\hline \multicolumn{3}{|l|}{ Laterality } \\
\hline Left & 3756 & 50.4 \\
\hline Right & 3515 & 47.2 \\
\hline Bilateral & 118 & 1.6 \\
\hline Unknown & 60 & 0.8 \\
\hline \multicolumn{3}{|c|}{ Histological type } \\
\hline Ductal & 6093 & 81.8 \\
\hline Lobular & 262 & 3.5 \\
\hline Other & 1094 & 14.7 \\
\hline \multicolumn{3}{|c|}{ Histological grade } \\
\hline I & 856 & 11.5 \\
\hline II & 2368 & 31.8 \\
\hline III & 2218 & 29.8 \\
\hline Unknown & 2007 & 26.9 \\
\hline \multicolumn{3}{|l|}{ Stage } \\
\hline I & 1653 & 22.2 \\
\hline II & 3491 & 46.9 \\
\hline III & 807 & 10.8 \\
\hline IV & 305 & 4.1 \\
\hline Unknown & 1193 & 16 \\
\hline \multicolumn{3}{|l|}{ ER } \\
\hline Positive & 3984 & 53.5 \\
\hline Negative & 2034 & 27.3 \\
\hline Unknown & 1431 & 19.2 \\
\hline \multicolumn{3}{|l|}{ PR } \\
\hline Positive & 3087 & 41.4 \\
\hline Negative & 2778 & 37.3 \\
\hline Unknown & 1584 & 21.3 \\
\hline \multicolumn{3}{|l|}{ HER2 } \\
\hline Positive & 1512 & 20.3 \\
\hline Negative & 1968 & 26.4 \\
\hline Unknown & 3969 & 53.3 \\
\hline \multicolumn{3}{|l|}{ Chemotherapy } \\
\hline Yes & 3607 & 48.4 \\
\hline No & 2858 & 38.4 \\
\hline Unknown & 984 & 13.2 \\
\hline
\end{tabular}

invasive lobular cancers. Of those known, $15.7 \%, 43.5 \%$, and $40.8 \%$ had grades I, II, or III cancer, respectively, $26.4 \%, 55.8 \%, 12.9 \%$, and $4.9 \%$ had stages I, II, III, and IV cancers at diagnosis, respectively, and $53.5 \%, 41.4 \%$, and $20.3 \%$ patients were diagnosed with ER-positive, PRpositive, and HER2-positive cancers, respectively. Of those known with completed tumor expression, $13.4 \%$ had triple- 


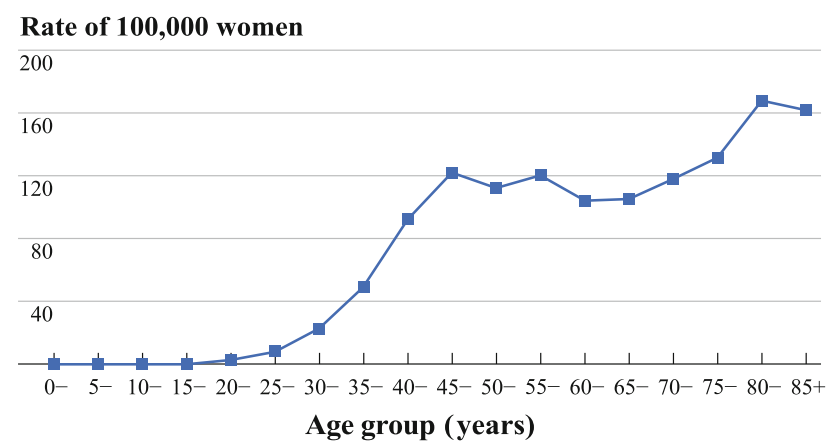

FIG. 1 Age-specific incidence rates for invasive breast cancer in Hong Kong, 1997-2001

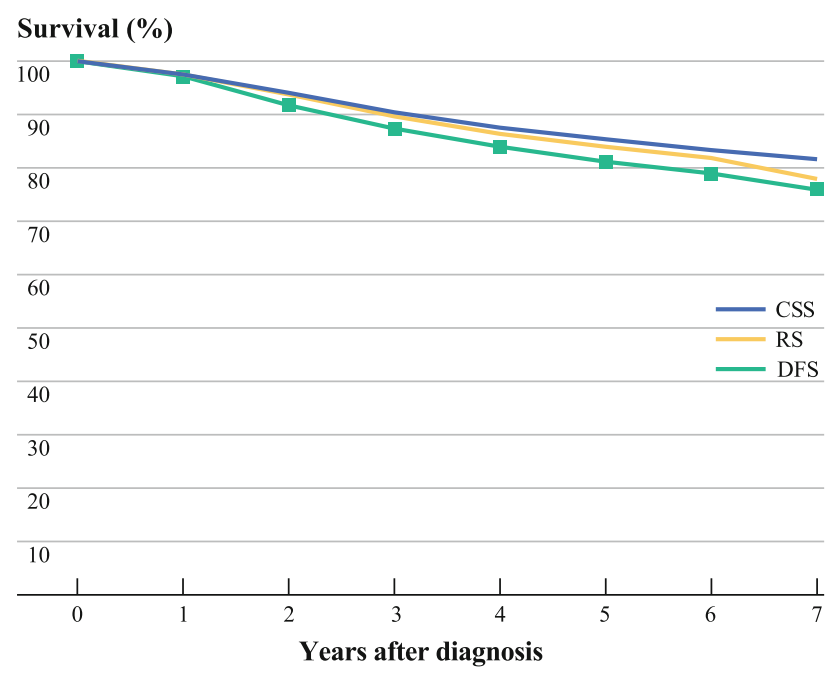

FIG. 2 Relative survival (RS), cancer-specific survival (CSS), and disease-free survival (DFS) of patients with invasive breast cancer in Hong Kong

negative cancers; $55.8 \%$ had chemotherapy, $60.2 \%$ had radiation therapy, and $85.7 \%$ of those who had ER-positive cancer received tamoxifen. At the end of the study, 1,872 (25.1\%) of the patients had either relapsed or have died of breast cancer. The median time to relapse or breast cancer death was 35.7 months and mean time was 29 months. Of patients who had invasive breast cancer, $27.5 \%$ had died by the end of study, of whom $65.2 \%$ died from breast cancer, 9.6\% died from cancers other than breast cancer, and $25.1 \%$ died from causes other than cancer. The RS, CSS, and DFS at 5 years were $84 \%, 85.2 \%$, and $81.2 \%$, respectively (Fig. 2). The stage-specific RS at 5 years were $97.5 \%, 87.8 \%, 66.2 \%$, and $19.3 \%$ for stages I, II, III, and IV, respectively (Fig. 3).

\section{DISCUSSION}

Cancer registries have been set up worldwide to provide information on cancers, such as breast cancer. This

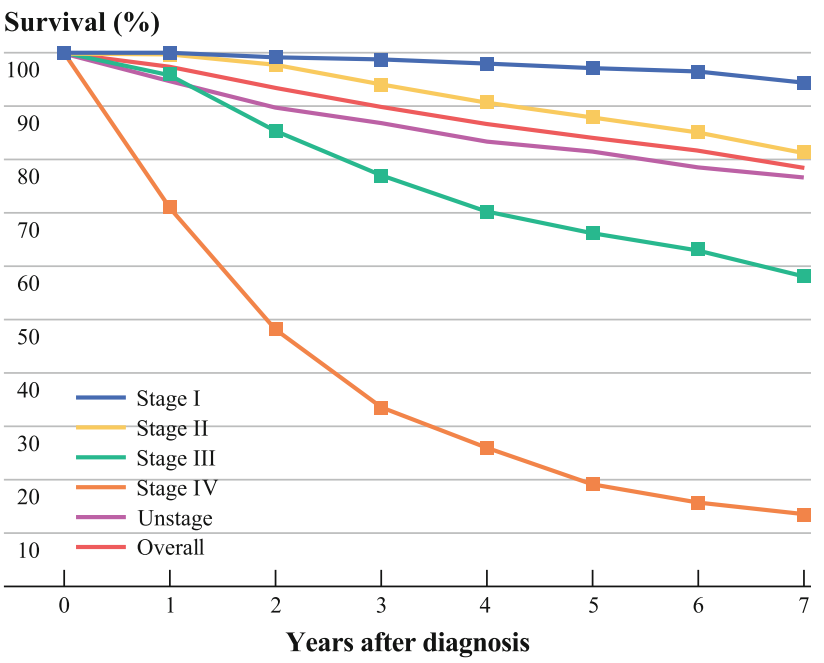

FIG. 3 Relative survival of patients with invasive breast cancer by stage at diagnosis in Hong Kong

information has been published in many western countries, but reports from Asia are generally from individual centers or combinations of a few registries or centers within a country rather than a complete population-based study. A study in Mainland China also found that the consistency in data collection between local registries may be variable. ${ }^{29}$ We therefore performed a first comprehensive populationbased breast cancer epidemiology and survival study in women in Hong Kong, Southern China, using the Hong Kong Cancer Registry database. A previous study performed by The Hong Kong Hereditary Breast Cancer Registry found that $84 \%$ of the women with breast cancer who reside in Hong Kong originated from Guangdong province in Southern Mainland China. ${ }^{30}$ Although nearly $70 \%$ of them were born in Hong Kong, more than $70 \%$ of these patients' parents originated and resided in Mainland China. Hong Kong is a unique place to study breast cancer trend in China because it was ruled by the British for 99 years and therefore is more westernized compared with the rest of China. Indeed, the incidence of breast cancer in Hong Kong, although lower than western countries, are among the highest in Asia, on par with Singapore and Japan, both of which are more developed and westernized areas within Asia. ${ }^{31-33}$ The offspring of Asian women, in particular Japanese, who have migrated to the United States, have been found to have increased breast cancer incidence compared with those residing in Japan. ${ }^{34}$ The risk of breast cancer of Asians born in the west is increased by sixfold compared with those born in the east, likely due to the change of lifestyle, which can influence a number of risk factors related to breast cancer, such as nutrition, reproductive, and hormonal factors. ${ }^{35}$ The incidence of breast cancer in Mainland China ranges from 10-60 per 100,000 . This depends strongly on the location where the 
incidence data has been obtained and is less in the rural areas of China. The incidence however has rapidly increased particularly in more developed cities, such as Shanghai, during the past decade where lifestyle is now similar to that of Hong Kong. ${ }^{36}$ With Hong Kong handed over to the People's Republic of China since 1997, under the ruling of "one country, two systems," Hong Kong has remained independent. The access of mainland Chinese migrants to Hong Kong, especially through marriages, has increased during the past 5 years. This is likely to result in a change of the disease pattern of breast cancer within Hong Kong during the next decade with migrants of different Chinese ancestries having different socioeconomic backgrounds and lifestyle. These may indirectly affect the risk of breast cancer. ${ }^{37}$ Therefore, this study will be important to serve as a baseline study of breast epidemiology in the region and assist worldwide international comparison studies where there is an increase influx of Chinese migrants from mainland China.

Survival information is not always available in studies performed by cancer registries worldwide. It has been known that mortality and survival rates can vary between countries. The role of population based cancer registries had evolved not only to report the incidence and trends of cancer but to include survival information, which has become increasingly important for better evaluation and planning of cancer control measures. ${ }^{38}$ The role of stage at presentation and stage-specific survival emphasizes the need for early diagnosis and treatment of cancer to achieve a better outcome. ${ }^{39}$ The age-standardized relative survival rate is the most commonly reported but is much underreported in Asian countries. A study on survival rates of five continents included information from Japan but none from China, ${ }^{40}$ and there have been various studies on survival information in Chinese but none population-based. ${ }^{41}$ More detailed population-based survival information, including stage-specific and cancer-specific survival, is even less well reported.

Our study found a relative survival of $84 \%$, which is comparable to that of other western reports and $87 \%$ from the SEER database during that same study period. ${ }^{42,43}$ The comparable cancer-specific survival of $85.2 \%$ with relative survival and the worsening survival associated with a later stage of diagnosis of the disease emphasizes the importance of the need for earlier diagnosis. Of those patients with known staging information, only $26.4 \%$ of our cohort presented with stage I disease; the majority presented with stage II or later disease. Although screening facilities are available in Hong Kong, we do not have a population screening program and patients have to attend screening on a voluntary basis. This may, in addition, be limited by financial constraints because insurance policy is still not widely practiced, and there is no government subsidy for screening. Only approximately $20 \%$ of women in Hong Kong practice breast screening likely due to the aforementioned constraints. ${ }^{11,44,45}$

Of those patients with known ER, PR, and HER2 receptor status, our cohort has a similar triple-negative rate compared with western data ( $13.4 \%$ vs. $11.2 \%)$. However, $60 \%$ of patients did not have HER 2 receptor status. This was likely due to the specific time period of study, where the use of targeted therapy, such as trastuzumab, was still not widely available, and therefore the HER2 status was not performed. Even when trastuzumab became available, the use was limited. Similar to screening, there are only limited subsidy support from the government and therefore financial constraints would limit its use and also the performance of testing for HER2 status. With the emergent of more targeted therapy, the knowledge of the status of hormonal receptors and HER2 receptors in our population, which was previously underreported in Asia, would be important for health care planning.

The strength of this study is the completeness and high degree of accuracy of the data collection. The limitations of the study are the lack of information on social background, such as education and income level, and risk factors, such as reproductive history, gynecological history, body weight, hormonal intake, nutritional information, and family history. The lack of details of screening practice and treatment data also provided a limited picture on breast cancer treatment and influence on the prognosis of the disease. This study's emphasis was on the reporting of the various tumor biology and various survival rates in our cohort, and hence, discussing risk factors, screening practice, and treatment information is beyond the scope of this study and will be reported in a separate study. With the full implementation of a population-wide computer medical record system in 2000 in Hong Kong, it is likely that such information would be easily accessible for data collection. A retrospective study of a large-scale data collection on such details on the present dataset is being implemented.

\section{CONCLUSIONS}

This study provides the first population-based analysis on epidemiological, pathological characteristics, and survival, including stage-specific and cancer-specific survival data for women with breast cancer in Hong Kong, Southern China. As a baseline study, this would provide information for further analysis on the association between risk factors and breast incidence in our locality and treatment modalities on the outcome of breast cancer. Further analysis with longer follow-up periods and a larger cohort would enrich the information for planning of screening, management, and preventative strategies in the Asia region and may 
indirectly benefit worldwide health planning due to the increase in Chinese migrants around the world.

ACKNOWLEDGMENT We thank the Dr. Ellen Li Charitable Foundation and Kuok Foundation for their continual support. We also thank members of the Hong Kong Breast Cancer Research group for their advice on the research: Drs. GKH Au, KKL Chan, MCM Chan, WC Chan, ACK Cheng, WWL Foo, LS Ho, BYK Lam, R Leung, SL Leung, MK Li, MY Luk, FCS Leung, TY Ng, M Poon, IS Soong, DTK Suen, DCT Wong, TT Wong, TK Yau, WMM Yeo, MWL Ying.

\section{CONFLICT OF INTEREST None.}

OPEN ACCESS This article is distributed under the terms of the Creative Commons Attribution Noncommercial License which permits any noncommercial use, distribution, and reproduction in any medium, provided the original author(s) and source are credited.

\section{REFERENCES}

1. Parkin DM, Fernandez LM. Use of statistics to assess the global burden of breast cancer. Breast J. 2006;12(Suppl 1):S70-80.

2. World Health Organization Medica Center "Cancer" 2011. http://www.who.int/mediacentre/factsheets/fs297/en/.

3. Zaky SS, Lund M, May KA, et al. The negative effect of triplenegative breast cancer on outcome after breast-conserving therapy. Ann Surg Oncol. 2011 Mar 26. [Epub ahead of print].

4. Gelber RP, McCarthy EP, Davis JW, Seto TB. Ethnic disparities in breast cancer management among Asian Americans and Pacific Islanders. Ann Surg Oncol. 2006;13:977-84.

5. Parkin DM, Bray F, Ferlay J, Pisani P. Global cancer statistics, 2002. CA Cancer J Clin. 2005;55:74-108.

6. Lin TM, Chen KP, MacMahon B. Epidemiologic characteristics of cancer of the breast in Taiwan. Cancer. 1971;27:1497-504.

7. Huang C-S, Lin C-H, Lu Y-S, Shen C-Y. Unique features of breast cancer in Asian women-breast cancer in Taiwan as an example. J Ster Biochem Mol Biol. 2010;118:300-3.

8. Tseng CH, Chong CK, Tai TY. Secular trend for mortality from breast cancer and the association between diabetes and breast cancer in Taiwan between 1995 and 2006. Diabetologia. 2009;52:240-6.

9. Shin H-R, Boniol M, Joubert C, et al. Secular trends in breast cancer mortality in five East Asian populations: Hong Kong, Japan, Korea, Singapore and Taiwan. Cancer Sci. 2010;101: 1241-6.

10. Tominaga S, Kuroishi T. Epidemiology of breast cancer in Japan. Cancer Lett. 1995;90:75-9.

11. Kwong A, Cheung PS, Wong AY, et al. The acceptance and feasibility of breast cancer screening in the east. Breast. 2008:17:42-50.

12. The Hong Kong Cancer Registry. http://www3.ha.org.hk/can cereg/default.asp.

13. Hong Kong Cancer Registry. In: Cancer Registry Annual Report. Hong Kong Hospital Authority; 2004.

14. Cancer incidence in five continents. Volume VIII. IARC Sci Publ. 2002:1-781

15. Hill DA, Nibbe A, Royce ME, et al. Method of detection and breast cancer survival disparities in Hispanic women. Cancer Epidemiol Bio Prev. 2010;19:2453-60.

16. Schmidt RT, Tsangaris TN, Cheek JH. Breast cancer in women under 35 years of age. Am J Surg. 1991;162:197-201.

17. Kouri EM, He Y, Winer EP, Keating NL. Influence of birthplace on breast cancer diagnosis and treatment for Hispanic women. Breast Cancer Res Treat. 2010;121:743-51.
18. Leung GM, Thach TQ, Chan E, et al. Short-term, medium-term, long-term, and lifetime risks of developing and dying of breast carcinoma in a westernized Chinese population: evidence from Hong Kong between 1976 and 2000. Cancer. 2005;103:501-8.

19. Feuer EJ, Wun LM, Boring CC, et al. The lifetime risk of developing breast cancer. J Nat Cancer Inst. 1993;85:892-7.

20. Kwong A, Cheung P, Chan S, Lau S. Breast cancer in Chinese women younger than age 40: are they different from their older counterparts? World J Surg. 2008;32:2554-61.

21. Swanson GM, Lin CS. Survival patterns among younger women with breast cancer: the effects of age, race, stage, and treatment. J Natl Cancer Inst Monogr. 1994:69-77.

22. Shin H-R, Masuyer E, Ferlay J, et al. Cancer in Asia: incidence rates based on data in cancer incidence in five continents IX (1998-2002). Asian Pac J Cancer Prev. 2010;11(Suppl 2): $11-6$

23. Bloom HJ, Richardson WW. Histological grading and prognosis in breast cancer; a study of 1409 cases of which 359 have been followed for 15 years. Br J Cancer. 1957;11:359-77.

24. Fleming ID. AJCC/TNM cancer staging, present and future. J Surg Oncol. 2001;77:233-6.

25. http://www.cancerstaging.org.

26. Brenner H, Hakulinen T. Up-to-date long-term survival curves of patients with cancer by period analysis. J Clin Oncol. 2002;20: 826-32.

27. Census and Statistics Department. Hong Kong Life Tables. 2004-2039. 2004. http://www.censtatd.gov.hk/products_and_ services/products/publications/statistical_report/population_and_ vital_events/index_cd_B112001604_dt_detail.jsp.

28. Dickman P, Hakulinen T, Voutilainen E. Surv3 relative survival analysis program version 3.01. Helsinki, Finland: Finnish Cancer Registry; 2002.

29. Yang L, Parkin DM, Whelan S, et al. Statistics on cancer in China: cancer registration in 2002. Eur J Cancer Prev. 2005; 14:329-35.

30. Kwong A, Wong LP, Wong HN, et al. Clinical and pathological characteristics of Chinese patients with BRCA-related breast cancer. Hugo J. 2009;3:63-76.

31. Leung JW. New modalities in breast imaging: digital mammography, positron emission tomography, and sestamibi scintimammography. Radiol Clin North Am. 2002;40:467-82.

32. Seow A, Duffy SW, McGee MA, et al. Breast cancer in Singapore: trends in incidence 1968-1992. Int J Epidemiol. 1996;25: $40-5$.

33. Minami Y, Tsubono Y, Nishino $\mathrm{Y}$, et al. The increase of female breast cancer incidence in Japan: emergence of birth cohort effect. Int J Cancer. 2004;108:901-6.

34. Deapen D, Liu L, Perkins C, et al. Rapidly rising breast cancer incidence rates among Asian-American women. Int $J$ Cancer. 2002;99:747-50.

35. Ziegler RG, Hoover RN, Pike MC, et al. Migration patterns and breast cancer risk in Asian-American women. $J$ Natl Cancer Inst. 1993;85:1819-27.

36. Linos E, Spanos D, Rosner BA, et al. Effects of reproductive and demographic changes on breast cancer incidence in China: a modeling analysis. J Natl Cancer Inst. 2008;100:1352-60.

37. Bray F, McCarron P, Parkin DM. The changing global patterns of female breast cancer incidence and mortality. Breast Cancer Res. 2004:6:229-39.

38. Parkin DM. The evolution of the population-based cancer registry. Nat Rev Cancer. 2006;6:603-12.

39. Parkin DM. The role of cancer registries in cancer control. Int $J$ Clin Oncol. 2008;13:102-11.

40. Coleman MP, Quaresma M, Berrino F, et al. Cancer survival in five continents: a worldwide population-based study (CONCORD). Lancet Oncol. 2008;9:730-56. 
41. Chen K, He M, Dong S, Wang J. [Incidence, mortality and survival rates of female breast cancer in Tianjin, China]. Zhonghua Zhong Liu Za Zhi. 2002;24:573-5.

42. Coleman MP, Gatta G, Verdecchia A, et al. EUROCARE-3 summary: cancer survival in Europe at the end of the 20th century. Ann Oncol. 2003;14(Suppl 5):v128-49.

43. Jemal A, Tiwari RC, Murray T, et al. Cancer statistics, 2004. CA Cancer J Clin. 2004;54:8-29.
44. Lui CY, Lam HS, Chan LK, et al. Opportunistic breast cancer screening in Hong Kong; a revisit of the Kwong Wah Hospital experience. Hong Kong Med J. 2007;13:106-13.

45. Balu-Maestro C, Chapellier C, Bleuse A, et al. Imaging in evaluation of response to neoadjuvant breast cancer treatment benefits of MRI. Breast Cancer Res Treat. 2002;72:145-52. 